\title{
Chagas Disease in Mexico: Report of 14 Cases of Chagasic Cardiomyopathy in Children
}

\author{
Paz María Salazar-Schettino, ${ }^{1}$ Margarita Cabrera-Bravo, ${ }^{1}$ Clara Vazquez-Antona, ${ }^{2}$ \\ Edgar Zenteno, ${ }^{1}$ Mariana De Alba-Alvarado, ${ }^{1}$ Elia Torres Gutierrez, ${ }^{1}$ \\ Yolanda Guevara Gomez, ${ }^{1}$ María Gabriela Perera-Salazar, ${ }^{3}$ \\ Guadalupe Garcia de la Torre ${ }^{4}$ and Martha Irene Bucio-Torres ${ }^{1}$
}

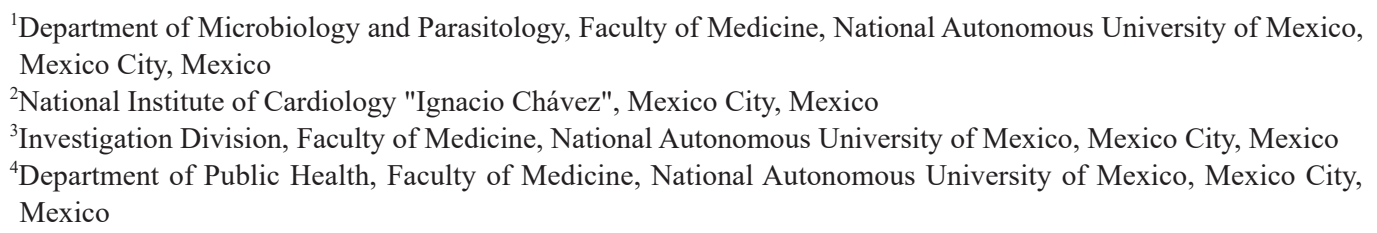

Chagas disease is a parasitic infection mainly found in Latin America; it is transmitted by a triatomine, also known as assassin bug or kissing bug. In humans, the parasite causes mostly cardiac disorders. Two-thirds of the Mexican territory are regarded as risk areas for vector transmission of Trypanosoma cruzi, the causal agent. The parasite can be found as a blood-borne trypomastigote or as an intracellular amastigote. The progression and severity of lesions could be due to frequent reinfections or to infection by highly virulent strains. A total of 3,327 individuals younger than 18 years old, living in risk areas for this disease in the rural setting of the States of Queretaro, San Luis Potosi, and Veracruz, underwent a seroepidemiological study. Among them, 37 subjects were seropositive for $T$. cruzi, and were studied to look for signs of cardiac pathology, which has only been reported in adults. A clinical record was prepared for all included individuals, and electrocardiography (ECG) and echocardiography (ECHO) studies were performed; 25 cases showed lesions compatible with the onset of Chagas cardiomyopathy. The other 12 patients showed either normal ECG and ECHO data or showed abnormal parameters that were not regarded as significant. Lesions found in the onset of Chagas cardiomyopathy in children are herein reported, along with 14 cases of cardiac pathology compatible with Chagas disease. Our results indicate that patients younger than 18 years can show a cardiac pathology similar to that observed in adults.

Keywords: cardiomyopathy; Chagas disease; Mexico; pediatric patients; Trypanosoma cruzi

Tohoku J. Exp. Med., 2016 November, 240 (3), 243-249. (C) 2016 Tohoku University Medical Press

\section{Introduction}

According to the WHO, Chagas disease is the third most important parasitic infection worldwide. Estimations indicated that in 2010 Mexico ranked third in the number of infected individuals, only after Argentina and Brazil (WHO 2015).

In 2006, the Pan American Health Organization (PAHO) estimated the existence of 1,100,000 individuals infected with Trypanosoma cruzi in Mexico, and of 29,500,000 individuals at risk of become infected (OPS and OMS 2006). Even though the disease is underreported in Mexico due to the absence of clinical or postmortem signs, the Secretariat of Health (Secretaria de Salud and DGAE 2015) reported 5,559 cases of patients between 25 and 44 years-old in the 2000-2012 period, with 371 deaths; 762 new cases were reported in 2013 with 41 deaths, 735 cases in 2014 and 1,095 in 2015.

Seroprevalence studies have been conducted in the Mexican States of San Luis Potosi, showing the prevalence of 6.3\% (46/734) (Aldana Cruz et al. 2009); in Queretaro, with the prevalence of $1.3 \%(11 / 826)$ (Salazar-Schettino et al. 2009), and in Veracruz, with the prevalence of $1.6 \%$ (624/9 782) (Salazar-Schettino et al. 2005).

There are 32 species of arthropod vectors for T. cruzi in Mexico, distributed throughout the country, and the endemic area for these vectors covers two-thirds of the Mexican territory; among them, the main intradomiciliary species are Triatoma barberi in 12 States, and Triatoma dimidiata in 16 (Tay et al. 1981; Salazar-Schettino et al. 2010).

Chronic cardiomyopathy has been described in Chagas

Received July 11, 2016; revised and accepted October 3, 2016. Published online November 26, 2016; doi: 10.1620/tjem.240.243.

Correspondence: Martha Irene Bucio Torres, Department of Microbiology and Parasitology, Faculty of Medicine, National Autonomous

University of Mexico, Edificio A, $2^{\circ}$ piso, Ciudad Universitaria, Circuito Escolar 04510, DF, Mexico.

e-mail: marbu@unam.mx 
disease since last century; this condition is usually observed 10-20 years after the acute stage. However, alterations compatible with cardiomyopathy were observed 18 months after the acute stage in a case report from Queretaro (Salazar-Schettino et al. 2009), thus emphasizing the importance of purposively seeking pediatric cases in endemic regions.

The pathogenesis of cardiac lesion in Chagas disease is very complex; lesions are mainly found in the autonomous nervous system and in myocardium. Autonomic disorders with rhythm alterations and sudden death have been described, or death by progressive myocardial insufficiency resulting in asystole (Chagas 1911; Chagas and Villela 1922). While the pathogenesis of the chronic disease is not fully understood yet, a growing consensus suggests that parasite persistence is required for lesion development; it is not known whether tissue damage is caused by parasiterelated factors, by the activation of an immunopathological process, or by autoimmune mechanisms (Cunha-Neto et al. 2011).

During chronic infections, parasite containment is achieved by a balance of the immune response and inflammation, which affects host tissues and may influence the progression of the disease; either an inefficient or an excessive immune response is harmful, since an increase in parasite load or in the inflammatory response may lead to tissue damage (Rassi and Marin-Neto 2010). The main pathogenic mechanisms mediated by the parasite, including autonomic disorders, alteration of the humoral and cellular immune response, and microvascular disorders, are shown in Fig. 1 (Teixeira et al. 2006; Marin-Neto et al. 2007; Marin-Neto and Rassi 2009; Rassi and Marin-Neto 2010).

Chagas cardiomyopathy only has been described in adult patients, especially when lesions are conspicuous dur- ing the chronic, symptomatic stage of the disease; male sex is predominant, and death usually occurs at 30-50 years of age by progressive cardiac insufficiency and rhythm disorders, with thromboembolism and cardiomegaly (Viotti et al. 2004, 2005; TDR and WHO 2007; Sociedad Argentina de Cardiología 2011; Ministerio de Salud de la Nación 2012). In contrast, clinical studies on these alterations in pediatric patients are scarce. This work is aimed to determine the cardiac pathology in patients younger than 18 years-old, seropositive for $T$. cruzi, by cardiologic clinical study with electrocardiography and echocardiography for early detection of incipient lesions compatible with Chagas cardiomyopathy.

\section{Patients and Methods}

In total, 3,327 subjects younger than 18 years-old, natives from the States of San Luis Potosi, Queretaro, and Veracruz (Fig. 2), were initially serum-screened by indirect ELISA. Reactive results were then confirmed in serum obtained by venous puncture by the ELISA and indirect immunofluorescence (IIF) methods, as previously described (Salazar-Schettino et al. 2005). As recommended by WHO/ PAHO, only those samples with positive results for both procedures were regarded as positive.

Thirty-seven cases of patients younger than 18 years-old, seropositive to T. cruzi, from the Mexican States of Queretaro, San Luis Potosi, and Veracruz were studied. A questionnaire was applied to all patients to record gender, age, and cohabitation with the vector (Segura et al. 2005); specimens of the triatomine species endemic in the region were shown to the patients for identification, and a clinical record ad hoc for Chagas's disease was prepared.

Validated indirect ELISA and IIF tests were used for serological confirmation. Dubious or discordant cases were confirmed by immunoblot (TDR and WHO 2007; Ministerio de Salud de la Nación 2012; Torres-Gutiérrez et al. 2015).

12-lead electrocardiography (standard ECG), two-dimensional

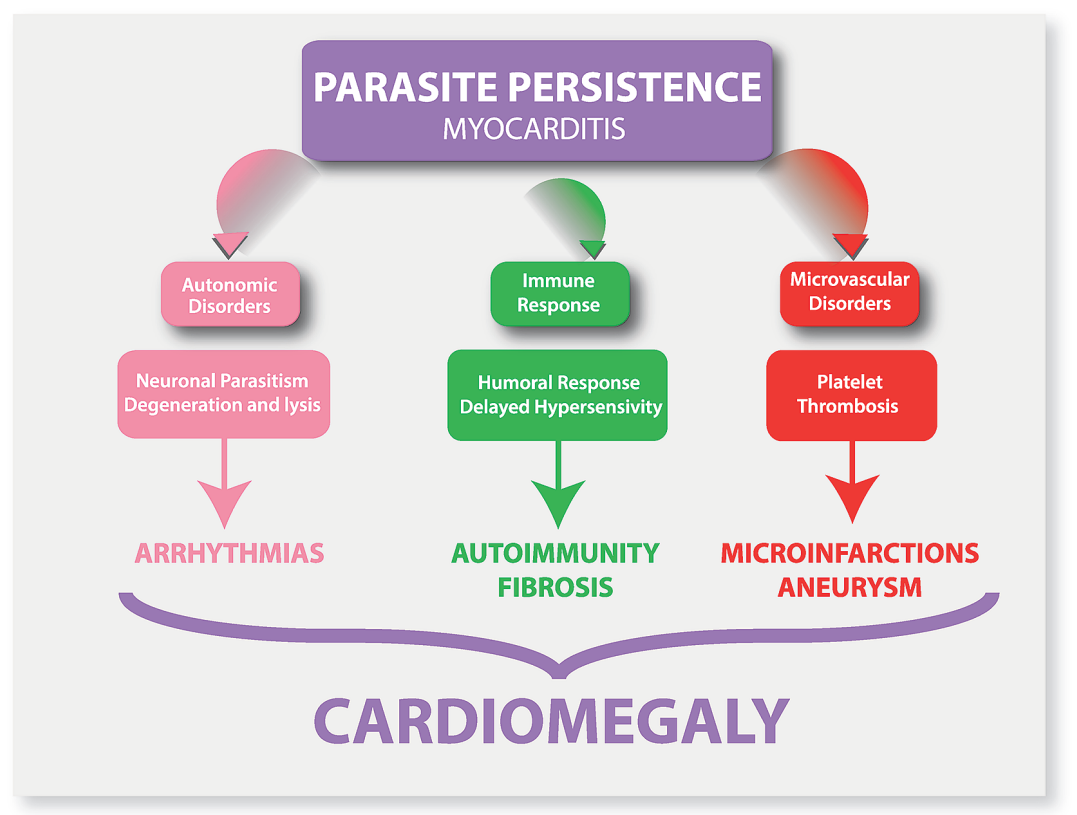

Fig. 1. Main mechanisms involved in chronic disease. 


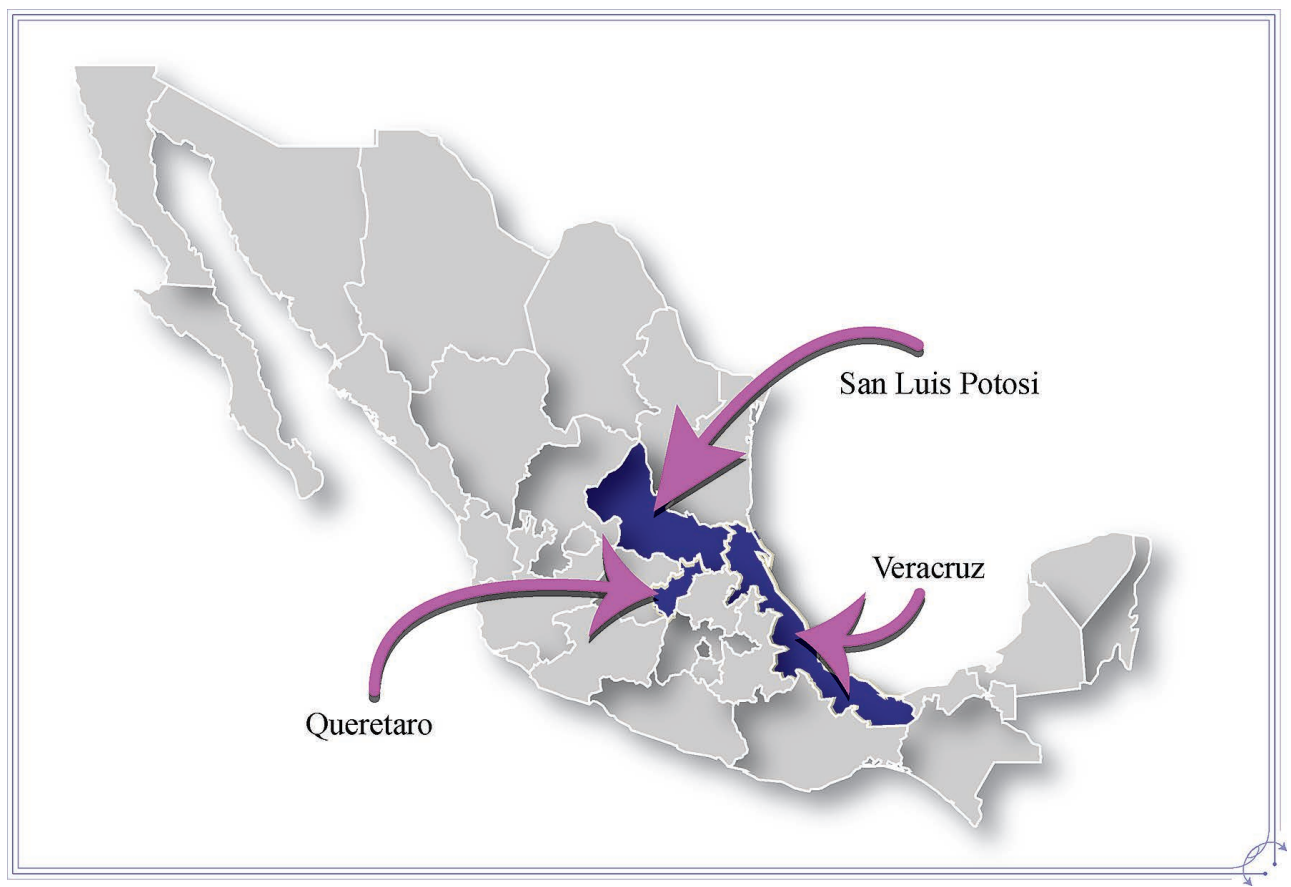

Fig. 2. Provenance of studied cases.

echocardiography, and standard Doppler (ECHO) studies were performed and interpreted at the Instituto Nacional de Cardiología "Dr. Ignacio Chavez".

Even though 40 seropositive individuals were initially detected, two subjects were excluded from the study after congenital heart malformations were found, and a third subject was excluded since she suffered from Down syndrome, leaving only 37 cases included. A familial study was performed in conjunction with the serologic confirmation of cases, to rule out mother-to-fetus transmission; all mothers were seronegative.

This study was approved by the Committees for Research, Ethics, and Biosafety at the Facultad de Medicina, Universidad Nacional Autonoma de Mexico. The parents or legal tutors of all patients read and signed an informed consent letter to enter the study.

\section{Results}

Among the 37 underage patients selected, 28 (75.7\%) were from San Luis Potosi, 7 (18.9\%) from Queretaro, and $2(5.4 \%)$ from Veracruz. With respect to sex, $22(59.5 \%)$ were males and 15 (40.5\%) were females. Patients were between 5 and 17 years-old at the beginning of the study, with a median of 14 years old. Cohabitation with vectors was demonstrated in 36 patients $(97.29 \%)$, and cohabitation with domestic animals in 33 (89.2\%).

For the sake of clarity, the cases under study were grouped based on the alterations found in ECG studies. Three groups were formed, based on seropositivity, clinical and epidemiological characterization, and on ECG and ECHO findings; the main parameter was the assessment of electrocardiographic record, followed by ECHO-determined lesions. Group 1 included 12 cases showing normal ECG and either normal ECHO or incipient lesions (with some parameter out of range, not regarded as significant) (Table 1). Group 2 included 11 cases showing abnormal ECG with incomplete right bundle branch block, and either normal ECHO or incipient lesions (septal and/or posterior wall hypertrophy) (Table 2). Group 3 included 14 cases; 12 showing abnormal ECG with complete block, incomplete branch block with left ventricle or right atrium growth, with arrhythmia or sinus bradycardia $(\leq 55$ beats $/ \mathrm{min}$ ) and either normal ECHO, incipient lesions (left ventricle, posterior wall, and/or interventricular septum hypertrophy), or abnormal ECHO (Table 3). The abnormal ECHO findings include septal hypokinesis, left ventricular ejection fraction (LVEF) $<57 \%(64 \pm 6)$, or pulmonary artery blood pressure (PABP) $>35 \mathrm{mmHg}$. Being pediatric population, cavity measures were compared according to the $\mathrm{Z}$-score value.

Indirect interrogation through the mothers and/or direct questions to the subjects under study about the background of the acute stage of the disease showed that 30 $(81.1 \%)$ were asymptomatic and $7(18.9 \%)$ reported symptoms and signs compatible with this stage; all patients showed fever and 6 described the traits of Romaña's sign; the time elapsed between this acute stage and the occurrence of cardiovascular symptoms was 2 to 7 years. Cardiovascular symptoms were present in 26 cases $(70.3 \%)$, with dyspnea, tachycardia, palpitations, or precordial pain. When assessing ECHO parameters, the most frequent lesions were interventricular and/or posterior wall hypertrophy, present in 14 individuals (37.84\%); 5 subjects showed septal hypertrophy, 4 showed posterior wall hypertrophy, and 5 showed both signs. Left ventricular ejection fraction (LVEF), regarded as an important indicator to evaluate diastolic function deterioration in Chagas's disease (TDR and WHO 2007; Viotti et al. 2004) was $<57 \%$ in 5 subjects $(13.51 \%)$, with readings between $50 \%$ and $53 \%$; growth in some cavity was determined in 3 cases $(8.11 \%)$, and the 
Table 1. Group 1. Patients with normal ECG and ECHO or with incipient lesions.

\begin{tabular}{|c|c|c|c|c|}
\hline \multirow[t]{2}{*}{ Sex } & & Female & Male & Total \\
\hline & & 8 & 4 & 12 \\
\hline Age & & $8-18$ & $7-17$ & $7-18$ \\
\hline Dyspnea & & 5 & 2 & 7 \\
\hline Irregular heart beats & & 3 & 1 & 4 \\
\hline Tachycardia & & 1 & 0 & 1 \\
\hline ECG & Normal & 8 & 4 & 12 \\
\hline \multirow[t]{2}{*}{$\mathrm{ECHO}$} & Normal & 7 & 4 & 11 \\
\hline & $\begin{array}{l}\text { Incipient } \\
\text { lesions }\end{array}$ & 1 & 0 & 1 \\
\hline
\end{tabular}

Incipient lesions $=$ With some parameter out of range but not considered significant (septal hypertrophy).

Table 2. Group 2. Patients with abnormal ECG and normal ECHO or with incipient lesions.

\begin{tabular}{|c|c|c|c|c|}
\hline \multirow{2}{*}{\multicolumn{2}{|c|}{ Sex }} & Female & Male & TOTAL \\
\hline & & 4 & 7 & 11 \\
\hline \multicolumn{2}{|l|}{ Age } & $11-15$ & $9-18$ & $9-18$ \\
\hline \multicolumn{2}{|c|}{ Dyspnea } & 3 & 3 & 6 \\
\hline \multicolumn{2}{|c|}{ Irregular heart beats } & 2 & 4 & 6 \\
\hline \multicolumn{2}{|c|}{ Tachycardia } & 2 & 1 & 3 \\
\hline ECG & IRBBB & 4 & 7 & 11 \\
\hline \multirow[t]{2}{*}{$\mathrm{ECHO}$} & Normal & 4 & 4 & 8 \\
\hline & Incipient lesions & 0 & 3 & 3 \\
\hline
\end{tabular}

$\mathrm{ECG}=$ electrocardiogram, $\mathrm{IRBBB}=$ incomplete blockade of the right bundle branch, $\mathrm{ECHO}=$ echocardiogram, Incipient lesions = parameters out of range that are not considered significant (septal hypertrophy and/or of the posterior wall).

values of pulmonary artery blood pressure were $>35$ $\mathrm{mmHg}$ in 4 cases $(10.81 \%)$; two of these cases are included in Group 2 (Table 2) and 2 are included in Group 3 (Table $3)$.

All 14 cases in Group 3 are cardiomyopathic patients, in contrast with those included in Groups 1 and 2. Lesions that could correspond to the onset of chronic cardiomyopathy are clearly visible only in Group 3 subjects.

\section{Discussion}

Until now, chagasic cardiomyopathy had only been described in adults; thus, the relevance of describing the 14 cardiopathic cases in pediatric age lies in the absence of other associated pathologies, since the parasitic infection is clearly responsible for the progression of these lesions.

In a literature review of Chagas disease in Mexico, two studies were found documenting two underage patients with probable Chagas cardiomyopathy. One patient, 15-year-old male from the State of Jalisco, was seropositive and showed positive xenodiagnoses; auscultation showed a splitting of the second sound, and electrocardiographic record showed A-V block (Tay et al. 1979). The other patient was a 13-year-old male from the State of Oaxaca, seropositive with arrhythmic cardiac sounds and splitting of the second sound in all foci; ECG showed incomplete $\mathrm{RBBB}$, increase in supraventricular automatism with 
Table 3. Group 3: patients with chagasic cardiomyopathy.

\begin{tabular}{|c|c|c|c|c|}
\hline \multirow{2}{*}{\multicolumn{2}{|c|}{ Sex }} & Female & Male & TOTAL \\
\hline & & 3 & 11 & 14 \\
\hline \multicolumn{2}{|l|}{ Age } & $6-16$ & $5-18$ & $5-18$ \\
\hline \multicolumn{2}{|c|}{ Dyspnea } & 2 & 7 & 9 \\
\hline \multicolumn{2}{|c|}{ Irregular heart beats } & 2 & 4 & 6 \\
\hline \multicolumn{2}{|c|}{ Tachycardia } & 1 & 1 & 2 \\
\hline \multirow[t]{7}{*}{ ECG } & Normal & 0 & 2 & 2 \\
\hline & IRBBB & 1 & 4 & 5 \\
\hline & IRBBB, B.S. & 1 & 2 & 3 \\
\hline & IRBBB, arrhythmia & 1 & 0 & 1 \\
\hline & IRBBB, hypertrophy of LV & 0 & 1 & 1 \\
\hline & IRBBB, hypertrophy of RA & 0 & 1 & 1 \\
\hline & RBBB & 0 & 1 & 1 \\
\hline \multirow[t]{3}{*}{$\mathrm{ECHO}$} & Normal & 2 & 1 & 3 \\
\hline & Incipient lesions & 1 & 4 & 5 \\
\hline & Abnormal & 0 & 6 & 6 \\
\hline
\end{tabular}

ECG, electrocardiogram; IRBBB = incomplete blockade of the right bundle of His, B.S = sinus bradycardia ( $\leq 55$ beats $/ \mathrm{min})$, LV, left ventricle, RA, right atrium, $\mathrm{RBBB}=$ complete blockade of the right bundle of His.

ECHO, echocardiogram; incipient lesions $=$ with parameters out of range that are not considered significant (hypertrophy of left ventricle, of the posterior wall and/or of the interventricular septum), abnormal = septal hypokinesis, left ventricle ejection fraction $(\mathrm{EF})<57 \%(64 \pm 6)$, pulmonary artery pressure $(\mathrm{PAP})>35 \mathrm{mmHg}$.

bigeminy PVC and a final diagnosis of chronic Chagas cardiomyopathy, which could be the first in our country (Salazar-Schettino et al. 1983).

Chest radiography was omitted in this study, since in our experience no alteration is evident in pediatric cases, and it has been reported that abnormal silhouette is not always present (Salazar-Schettino et al. 1983; TDR and WHO 2007; Sociedad Argentina de Cardiología 2011; Ministerio de Salud de la Nación 2012); however, it is noteworthy the presence of septal and posterior wall hypertrophy in the ECHO tests of 14 patients. As previously mentioned, these lesions are result of an inflammatory and fibrotic process, as a consequence of a type IV immune response with delayed hypersensitivity, activation of memory $\mathrm{T}$ cells, and mononuclear cell recruitment to the inflammation site. In these cases, a reinfection caused by a demonstrated continued cohabitation with the vector favors chronicity and lesion progression, as demonstrated by Dr. Chagas himself (Chagas 1911; Tarleton 1995; Andrade 1999; Marin-Neto et al. 2007; Salazar-Schettino et al. 2009; Rassi and Marin-Neto 2010).

Septal or parietal hypertrophy causes an abnormal motility of cavities with the ensuing deterioration of cardiac function, and this would explain the abnormal LVEF values in 5 patients. The ensuing pulmonary hypertension in these cases may not be solely due to a functional impairment of the organ, but also to a reduced microvascular circulation caused by an increase in platelet aggregation and endothelial adhesion, with formation of microthrombi (Rassi and Marin-Neto 2010).

Conduction and rhythm alterations shown in the ECG of some cases (Tables 2 and 3 ) could be due to myocardial fibrosis present in the genesis of tachyarrhythmias (ventricular tachycardia or fibrillation), the main causes of sudden death in chronic Chagasic patients; by blocking the cardiac impulse, fibrosis reduces conduction speed, which is also affected by the presence of collagen fibers between muscle bundles (Marin-Neto et al. 2007).

Some pediatric patients in our study come from rural areas in Queretaro. Triatoma barberi has been identified as the main $T$. cruzi vector in this region, while $T$. dimidiata is the main vector identified in the cases from Veracruz and San Luis Potosi; both arthropods are regarded as intradomiciliary pests (Salazar-Schettino et al. 2010). The cases from San Luis Potosi and Veracruz are from a geographical region known as "Huasteca", a zone regarded as endemic for triatomines, with all physiographical and bioclimatic conditions to favor the transmission dynamics for T. cruzi 
(Curto de Casas et al. 1999). Based on these results, it would be advisable that health authorities took actions to determine the active transmission of the infection in these regions.

The analysis of our cases confirms that severe lesions are more frequent in male patients, as previously described (Ministerio de Salud de la Nación 2012). It is remarkable that the ECHO studies of these patients showed an abnormal isovolumetric relaxation time in 27 of the 37 cases; this has been pointed out by Acquatella et al. (2011) as a frequent alteration in asymptomatic adult patients.

Cases in Group 3 are cardiomyopathic patients, in contrast with those included in Groups 1 and 2; they could be indicative of the onset of chronic cardiomyopathy. According to Acquatella, the cases of chronic Chagas cardiomyopathy could be asymptomatic or symptomatic; about three quarters of all seropositive cases are asymptomatic with normal ECG and regarded as being in an "indeterminate" stage (chronic asymptomatic), and the presence of ECG abnormalities implies disease progression in studies on adults (Acquatella et al. 2011, 2013). Considering this, the detection of these incipient lesions will allow us to determine the onset of cardiac lesions caused by $\mathrm{T}$. cruzi, because at pediatric ages there is no comorbidity with other pathologies related to cardiovascular impairment that are frequent in adults, such as systemic arterial hypertension, dyslipidemias, diabetes, and even alcoholism.

It is crucial to implement actions for early case detection, with an emphasis in pediatric ages, to determine not only the active transmission of the infection but to provide appropriate and timely antiparasitic treatment in order to avoid irreversible lesions (Salazar-Schettino et al. 2005, 2007). The findings shown in Tables 1, 2, and 3 evidence the onset and probably the progression of cardiac pathology, and they should be considered for the therapeutic handling and vigilance in seropositive children.

\section{Acknowledgments}

This study was partially financed by DGAPA/PAPIIT, Grants IN-204710, IN-211613, IT-200913 and Faculty of Medicine, UNAM. Thanks to the Health Secretariat of the States of Queretaro, Veracruz, and San Luis Potosi for their support in case follow-up and Dr. Carlos Zamora González for the ECG interpretation.

\section{Conflict of Interest}

The authors declare no conflict of interest.

\section{References}

Acquatella, H., Gómez, J.R. \& Puigbó, J.J. (2013) Imagenología en el diagnóstico y el pronóstico de la enfermedad de Chagas. Rev. Argent. Cardiol., 81, 184-195.

Acquatella, H., Puibó, J.J., Gómez, J.R., Catalioti, F., Mendoza, I., Noya, B., Noya, O. \& Sánchez, I. (2011) Utilidad de la ecocardiografía/Doppler en la enfermedad de Chagas. Gac. Med. Caracas, 119, 274-286.

Aldana Cruz, O., Escobedo de la Peña, J., Velasco Castrejon, O. \& Guzmán Bracho, C. (2009) Seroprevalencia de la Enfermedad de Chagas en Tamazunchale, San Luis Potosi. Enf. Infec. Microbiol., 29, 107-110.

Andrade, Z.A. (1999) Immunopathology of Chagas disease. Mem. Inst. Oswaldo Cruz, 94, 71-80.

Chagas, C. (1911) Nova entidade morbida do homem: rezumo geral de estudos etiolojicos e clinicos. Mem. Inst. Oswaldo Cruz, 3, 219-275.

Chagas, C. \& Villela, E. (1922) Forma cardíaca da Trypanosomiase Americana. Mem. Inst. Oswaldo Cruz, 14, 5-61.

Cunha-Neto, E., Teixeira, P.C., Nogueira, L.G. \& Kalil, J. (2011) Chapter 6 - Autoimmunity. In Advances in Parasitology Chagas Disease, Part B, edited by Weiss, L.M. \& Tanowitz, H.B. Academic Press, San Diego, CA, pp. 129-152.

Curto de Casas, S., Carcavallo, R., Galíndez-Girón, I. \& Burgos, J. (1999) Bioclimatic factors and zones of life. In Atlas of Chagas' disease vectors in the Americas Vol III, edited by Carcavallo, I., Galíndez-Girón, J. \& Jurberg, H.L. Editora Fiocruz, Rio de Janeiro, pp. 793-838.

Marin-Neto, J.A., Cunha-Neto, E., Maciel, B.C. \& Simões, M.V. (2007) Pathogenesis of chronic Chagas heart disease. Circulation, 115, 1109-1123.

Marin-Neto, J.A. \& Rassi, A.J. (2009) Actualización sobre la cardiopatía de la enfermedad de Chagas en el primer centenario de su descubrimiento. Rev. Esp. Cardiol., 62, 12111216.

Ministerio de Salud de la Nación (2012) Guías para la atención al paciente infectado con Trypanosoma cruzi (Enfermedad de Chagas), edited by Ministerio de Salud de la Nación, Buenos Aires, Argentina, p. 79.

Organización Panamericana de la Salud and Organización Mundial de la Salud (OPS \& OMS) (2006) Estimación cuantitativa de la enfermedad de Chagas en las Américas, edited by Jean, J. and Roberto, S., OPS, Montevideo, Uruguay.

Rassi, A. \& Marin-Neto, J.A. (2010) Chagas disease. Lancet, 375, 1388-1402.

Salazar-Schettino, P.M., De Haro Arteaga, I. \& Cabrera Bravo, M. (2005) Tres especies de triatominos y su importancia como vectores de Trypanosoma cruzi en México. Medicina (Buenos Aires), 65, 63-69.

Salazar-Schettino, P.M., Perera, R., Ruiz-Hernandez, A.L., Bucio Torres, M.I., Zamora-Gonzalez, C., Cabrera-Bravo, M. \& Harnden, A. (2009) Chagas disease as a cause of symptomatic chronic myocardopathy in Mexican children. Pediatr. Infect. Dis. J., 28, 1011-1013.

Salazar-Schettino, P.M., Rojas, G., Bucio, M., Cabrera, M., García, G., Ruiz, A., Guevara, Y. \& Tapia, R. (2007) Seroprevalencia de anticuerpos contra Trypanosoma cruzi y su asociación con factores de riesgo en menores de 18 años de Veracruz, México. Rev. Panam. Salud Publica, 22, 75-82.

Salazar-Schettino, P.M., Rojas-Wastavino, G.E., Cabrera Bravo, M., Bucio-Torres, M.I., Martínez-Ibarra, J.A., MonroyEscobar, M.C.R.R., Antonieta, Guevara Gómez, Y., Vences Blanco, M.O., Ruiz Hernández, A.L. \& Torres Gutiérrez, E. (2010) A revision of thirteen species of Triamoniae (Hemiptera:Reduviidae) vectors of Chagas disease in Mexico. Journal of the Selva Andina Research Society, 1, 57-80.

Salazar-Schettino, P.M., Tay, J., Ontiveros, A., Jiménez, J., De Haro, I., Bucio, M.I. \& Ruiz Hernández, A.L. (1983) Enfermedad de Chagas en México. Presentación de casos clínicos. Rev. Fac. Med. UNAM, 25, 77-82.

Secretaria de Salud \& Dirección General de Epidemiología (DGAE) (2015) Anuarios de Morbilidad y Mortalidad de la Dirección General de Epidemiología de la Secretaria de Salud, México.

[Cited: September 13, 2016]

http://www.epidemiologia.salud.gob.mx/anuario/html/ anuarios.html

http://www.epidemiologia.salud.gob.mx/dgae/infoepid/publi caciones mortalidad.html. 
[Accessed: September 13, 2016].

Segura, E.L., Escobar-Mesa, A., Grupo de Estudio sobre la Enfermedad de Chagas (2005) Epidemiología de la enfermedad de Chagas en el estado de Veracruz. Salud Pública Méx., 47, 201-208.

Sociedad Argentina de Cardiología (2011) Consenso de Enfermedad de Chagas-Mazza. Rev. Argent. Cardiol., 79, 544-564.

Special Programme for Research and Training in Tropical Diseases and World Health Organization (TDR and WHO) (2007) Reporte sobre la enfermedad de Chagas, edited by Guhl, F. and Lazdins-Helds, J.K., World Health Organization, Geneva, p. 104.

Tarleton, R.L. (1995) The role of T cells in Trypanosoma cruzi infections. Parasitol. Today, 11, 7-9.

Tay, J., Salazar S, P.M., Bucio, M.I., Zarate, R. \& Zarate, L. (1981) Estado actual sobre nuestros conocimientos sobre la enfermedad de Chagas en la República Mexicana. Rev. Soc. Bras. Med. Trop., 14, 29-67.

Tay, J., Salazar Schettino, P.M., Velasco Cedano, M., De Haro Arteaga, I., García Yáñez, Y. \& Gutiérrez Quiróz, M. (1979) Epidemiology of Chagas' disease in State of Jalisco, Republic of Mexico. Salud Pública Mex., 21, 145-149.
Teixeira, A.R.L., Nascimento, R.J. \& Sturm, N.R. (2006) Evolution and pathology in Chagas disease: a review. Mem. Inst. Oswaldo Cruz, 101, 463-491.

Torres-Gutiérrez, E., Barrios-Palacios, D., Ruiz-Hernández, A.L., Cabrera-Bravo, M., Guevara-Gómez, Y., Rojas-Wastavino, G., Salazar-Schettino, P.M. \& Bucio-Torres, M.I. (2015) Identification of immunodominant components of an isolate of Trypanosoma cruzi by immunoblot and its standardization for diagnostic purposes. Gac. Med. Mex., 151, 6-13.

Viotti, R.J., Vigliano, C., Laucella, S., Lococo, B., Petti, M., Bertocchi, G., Ruiz Vera, B. \& Armenti, H. (2004) Value of echocardiography for diagnosis and prognosis of chronic Chagas disease cardiomyopathy without heart failure. Heart, 90, 655-660.

Viotti, R., Vigliano, C., Lococo, B., Petti, M., Bertocchi, G., Alvarez, M.G. \& Armenti, A. (2005) Clinical predictors of chronic chagasic myocarditis progression. Rev. Esp. Cardiol., 58, 1037-1044.

World Health Organization (WHO) (2015) Chagas disease in Latin America: an epidemiological update based on 2010 estimates. Weekly Epidemiological Record, 90, 33-44. 